\title{
Indonesia Solar Power Study Using Secondary Data
}

\section{Winarso PA*}

Indonesia State College of Meteorology and Geophysics, Indonesia

*Corresponding author: Winarso PA, Indonesia State College of Meteorology and Geophysics, Indonesia, Tel: +0080066291011; E-mail: pawinarso@gmail.com Received date: Jan 19, 2017; Accepted date: Feb 02, 2017; Published date: Feb 06, 2017

Copyright: @ 2017 Winarso PA. This is an open-access article distributed under the terms of the Creative Commons Attribution License, which permits unrestricted use, distribution, and reproduction in any medium, provided the original author and source are credited.

\begin{abstract}
Indonesia is situated in tropical area which receives a lot of solar energy every year. Unfortunately, the applying of solar energy as the one energy sources is still have many problems such low efficiency and more expensive than fossil fuel. Another problem is that there is no actual data in experimental based which shows the actual solar energy received annually. Thus the massive usage of solar power in term of cost-effective is hard to be determined.
\end{abstract}

Indonesia happens to be ideal sites for solar energy production and utilization because of their geographical locations. Moreover, some remote areas are among the best sites to develop small scale solar electric generating plants. Hence the this country may exploit this natural resource to the advantage and work together with the international donor community to gain the means and knowledge necessary for developing sustainable energy technologies in Indonesia.

The objective of this study is to determine the theoretical potential of solar irradiation in Indonesia by several approximations from global up to regional point of view to investigate the favorable places of the potential solar radiation to convert in the electricity power. This global point of view may be subjected to have global findings of the specific areas favorable for obtaining the solar energy conversion for electricity. From the regional point of view, the development of timing of the sun shining may derive from rainfall pattern, where the more rainfall received over certain areas. The second object; they may describe more cloud development to reduce sun shining as wheel as sun radiation. The result may give more detail the potential areas of the sun radiation to be converted into solar power for electricity.

Keywords: Solar energy; Photosynthesis; Atmosphere; Solar irradiance

\section{Introduction}

Solar energy, radiant light and heat from the sun, has been harnessed by humans since ancient times using a range of everevolving technologies. Solar energy is the radiant (light and heat) energy produced by the sun. The solar energy that reaches the earth can be used to produce electricity or heat through the use of solar collectors (http://www.keu92.org/uploads/Search\%20engineering/The\%20Use $\% 20$ Of\% $20 \% 20$ Solar\%20Energy\%20In\%20Electricity\%20Production.pdf). As an example, a closed car can be viewed as a solar collector-the light energy that passes through the window glass is absorbed by the car's interior and is converted into heat energy, which becomes trapped inside the vehicle. In optimal areas, the amount of solar energy falling on an area the size of a basketball field, in thermal energy terms, is equivalent to about 650 barrels of oil a year. Solar energy is a renewable resource whose use does not affect its future supply [1]. Solar energy technologies include solar heating, solar photovoltaic, solar thermal electricity and solar architecture which can make considerable contributions to solving some of the most urgent problems the world now faces. Solar technologies are broadly characterized as either passive solar or active solar depending on the way they capture, convert and distribute solar energy. Active solar techniques include the use of photovoltaic panels and solar thermal collectors to harness the energy. Passive solar techniques include orienting a building to the
Sun, selecting materials with favorable thermal mass or light dispersing properties, and designing spaces that naturally circulate air.

The Earth receives 174 pet watts or represents a factor of 1015 watts of incoming solar radiation (insolation) at the upper atmosphere. Approximately $30 \%$ is reflected back to space while the rest is absorbed by clouds, oceans and land masses. The spectrum of solar light at the Earth's surface is mostly spread across the visible and near-infrared ranges with a small part in the near-ultraviolet. Earth's land surface, oceans and atmosphere absorb solar radiation, and this raises their temperature. Warm air containing evaporated water from the oceans rises, causing atmospheric circulation or convection [2-5]. When the air reaches a high altitude, where the temperature is low, water vapour condenses into clouds, which rain onto the Earth's surface, completing the water cycle. The latent heat of water condensation amplifies convection, producing atmospheric phenomena such as wind, cyclones and anticyclones. Sunlight absorbed by the oceans and land masses keeps the surface at an average temperature of $14^{\circ} \mathrm{C}$. By photosynthesis green plants convert solar energy into chemical energy, which produces food, wood and the biomass from which fossil fuels are derived. The total solar energy absorbed by Earth's atmosphere, oceans and land masses is approximately 3,850,000 exajoules (EJ) or equal with a factor of 1018 joules per year. In 2002, this was more energy in one hour than the world used in one year (http://eesc.columbia.edu/ courses/ees/climate/lectures/radiation/). Photosynthesis captures approximately 3,000 EJ per year in biomass. The amount of solar energy reaching the surface of the planet is so vast that in one year it is about twice as much as will ever be obtained from all of the Earth's non-renewable resources of coal, oil, natural gas, and mined uranium 
combined. Solar energy can be harnessed in different levels around the world. Depending on a geographical location the closer to the equator the more potential solar energy is available.

Solar energy development in Indonesia is still wide open. But alas, the government does not to have a strong desire to develop the potential of solar energy into electrical energy in particular. Actually, if it is developed optimally, solar energy can be one of the solutions to the depleted electricity energy supply. The one option open for further development is solar energy development. Solar energy use is still limited to research such as for agricultural or household activities, and has not been used as electrical energy.

Despite the acknowledgment that Indonesia's solar panels technology is far behind that of the developed countries, the use of solar panels is not really that complicated (http://www.ugm.ac.id/id/news/ 5549-solar.energy.development.is.wide.open). The panel can be directly placed in the home roofs and then connected to an existing power grid from PLN (Indonesia Power Electrical Institution). It is simple and can be placed on the resident's roofs, and then it needs to get connected to PLN's electricity grid. Running with the time, the used of solar energy in Indonesia more wide and seems to be supported with the condition that the potential area to be informed widely. As we know that Indonesia having more cloudy and rainy area as the tropical countries, lacking the proper information with regard of the meteorological point of view they may cause the friction the used solar energy for the people in Indonesia.

This paper want to describe and to explain the mapping of the solar condition especially duration of the sun shining over maritime continent of Indonesia where this parameter to convert in the solar energy condition over Indonesia. The mapping of the solar radiation over Indonesia maritime continent may not be published by the representative institution up to the present time so only little information to be available and less. This paper may start to discuss the global; point of view to present the global point of view of the solar energy, then this global result may combine with the seasonal condition over maritime continent. Where there are two consecutive season namely wet and dry season. Studying and exploring the season may develop the cloudy and cloudless condition with looking into the yearly rainfall type over most of the area. The data are collected from several sources as secondary data, but this paper may guide the mapping study of solar energy condition more deeply using primary data especially solar radiation.

\section{Methodology}

Solar Power is the energy generated by sunlight. Solar energy is being increasingly adopted throughout the globe because of its environmental benefits. This use of energy produces no waste and does not give out any harmful emissions. Also, it does not put strain on the Earth's ecosystem by using up too much land space, as it requires minimal machinery to operate. Sunlight is actually the Earth's primary source of energy. For instance, it makes possible the photosynthesis process of plants, algae and bacteria that maintains the atmosphere's level of oxygen thus making life possible as we know it. The amount of energy generated only by photosynthesis on Earth's organisms is about six times larger than the whole human power consumption [6,7].

There are two ways of converting sunlight energy into electricity: directly or indirectly.
Direct conversion is achieved by using Solar Panels, also called Photo Voltaic (PV) Arrays. Most solar panels are constructed with silicon PV cells, which are somewhat analogous to the chlorophyll used by living organisms. Solar Panels can be installed on the ground - on country-side houses or massive power plants- or on rooftops for individual use.

Indirect conversion is achieved by concentrating sunlight using lenses or mirrors to generate heat. The heat is then transferred to a transfer fluid for a conventional power plant or it can even be combined with PV arrays to improve their efficiency. It is the same basic process as using a magnifying glass to burn something.

In this study try to collect some data to have strong relation with the amount solar radiation receiving over the earth's surface where up to present time this data to sparse or no data. Due to the lack of the understanding of the role sun radiation data, over Indonesia only few places to observe and to record sun's radiation such as the agriculture meteorological research institution over remote area for agricultural purpose. With the developing the solar power, the current condition has no change without less priority such that it may decelerate the solar power study to be developed as the power for the electricity. To overcome, there should be explored from the global and regional point of view to have idea how much the solar power condition over Indonesia maritime continent.

The global point of view availability of the solar power may be presented in the beginning of this study's discussion to give the global feature solar power for the electricity. This step may give the global perspective of availability solar power to be explored further in the regional and local scales point of views. Then developing and exploring the meteorological in the regional and local scales may encourage the understanding of the solar power condition especially the solarinsolation (duration of the sun shining over certain object such as Photo Voltaic). Where the longer duration of the sun shining may support the more energy (heat) may be absorbed by the PV to be used for the electricity. These steps may develop in this study to exploring the map study of the power energy in Indonesia.

\section{Discussion}

Exploring the solar power over Indonesia maritime continent, this paper may start from the solar radiation that they are received every day from the sun. These data may give the global perspective of the of the sun energy received by the surface as follows (Figure 1).

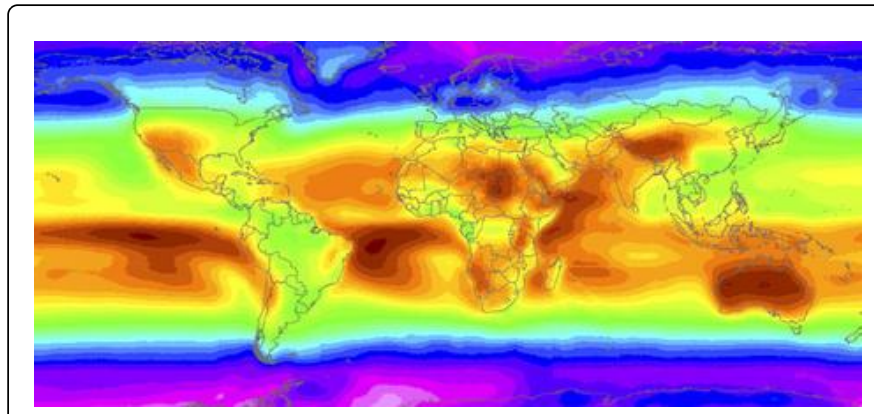

Figure 1: The red present the solar energy received by the earth, the red-brown present maximum solar energy (sources from US and European Satellites). 
Red shows the regions that receive the most sun, such as the middle of the Pacific Ocean and the Sahara Desert in Niger, followed by orange, yellow, green, blue, purple and pink. Australia gleams a bright red on the NASA map based upon data collected by US and European satellites. From this starting point, most of the large oceans (Pacific-, Atlantic- and Indian Oceans) and the desert over the continent except America have potential area receiving of the solar energy. Indonesia maritime continent has good area over the southern hemisphere area than northern and especially over the middle and eastern of the area. Further exploration concerning with initial finding may be discussed in the last section [8-12].

Further expansions for the solar energy data may be developed into the solar power plant for the global perspective include studying for the possibility over Indonesia maritime continent. As from the beginning global condition over southern hemisphere of middle and eastern Indonesia maritime continent, looking from the global perspective of the solar energy to be converted into solar power plant, it can be presented in the Figure 2 .

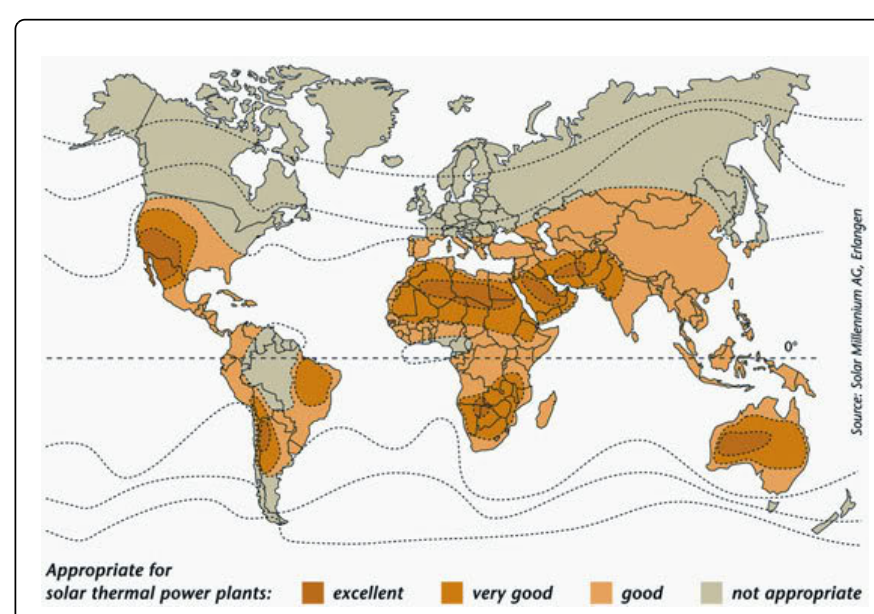

Figure 2: Global map may be suitable for the solar power plant (IEA).

From this global solar power plant, there is a little change from the global perspective of the solar energy but there are similarity with previous map that area having very god and excellent condition for solar thermal power plants mostly over the dry condition over land/ continent. There are over America-, Africa-, Asia- and AustraliaContinents. Indonesia maritime continent area may be generalized as the good solar power plant. Then from this map may be derived the global perspective of the availability amount of the solar energy to be describe in the next following map by the global solar power energy as follows (Figure 3).

This map may give the global solar energy to be converted into solar power plant such that Indonesia has annual range of the Solar Energy between 1300-1600 KW hour/meter square in general consideration of the annual average solar energy to be converted in the solar power of electricity. For general computation for local and regional point of view, the meteorological approach may be applied especially to determine the potential duration of the sun shining over the surface in Indonesia.

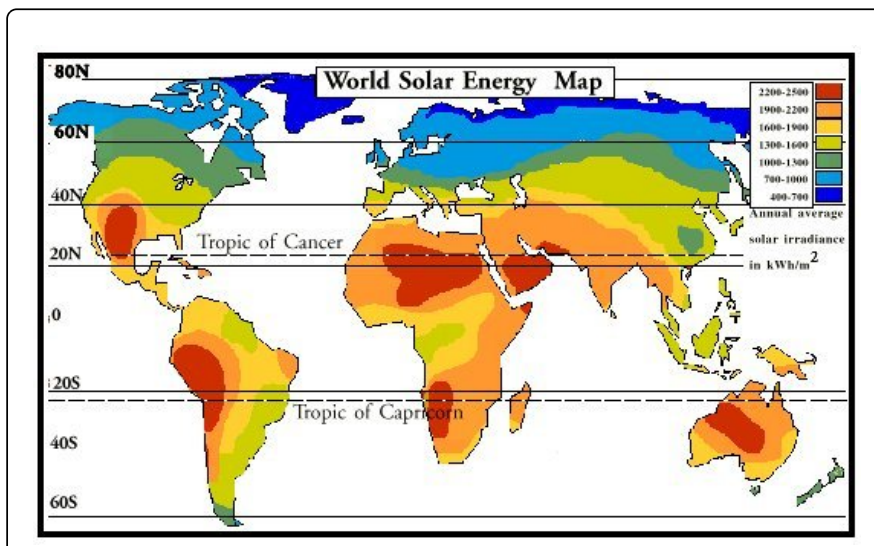

Figure 3: World solar energy (EIA).

As we know from the climatologically point of view such as rainfall type, this type may be represented as the rainfall may fall over certain areas such as Indonesia. The total number of the rainfall fur further determination may arrive in the total amount of cloud to be prevailed over certain period at certain area.

Less of the rainfall may correlate with less of the cloud and good longer period of the sun shining over the surface, reversal for the more rainfall may correlate with more cloud cover to have short period of sun shining. Indonesia maritime continent area has three rainfall types namely,

- Monsoonal type having rainfall during wet season and less rainfall during dry season.

- Equatorial type having rainfall during all the year with more rainfall during sun declination over the equator line (March/April and September/October).

- Local type having reversal with monsoonal type and some area having less of rainfall.

Further discussion to study further of the rainfall type over Indonesia maritime continent, the next following Figure may be presented as follows,

Based upon the Figure 4 in above and further elaborated with the rainfall type the monsoonal- and local-type with less of the rainfall lies over eastern of Java, Bali, Lombok up to Timor island (monsoonal rainfall type), most of several areas over North and Central Celebes, most of Moluccas islands and some area of western Papua (local rainfall type) as the good area to be exploited the solar energy for solar energy power.

To do this, it is better if further study to be proposed to utilize the solar power mapping using proper data. 
Citation: Winarso PA (2017) Indonesia Solar Power Study Using Secondary Data. J Climatol Weather Forecasting 5: 191. doi: $10.4172 / 2332-2594.1000191$

Page 4 of 5

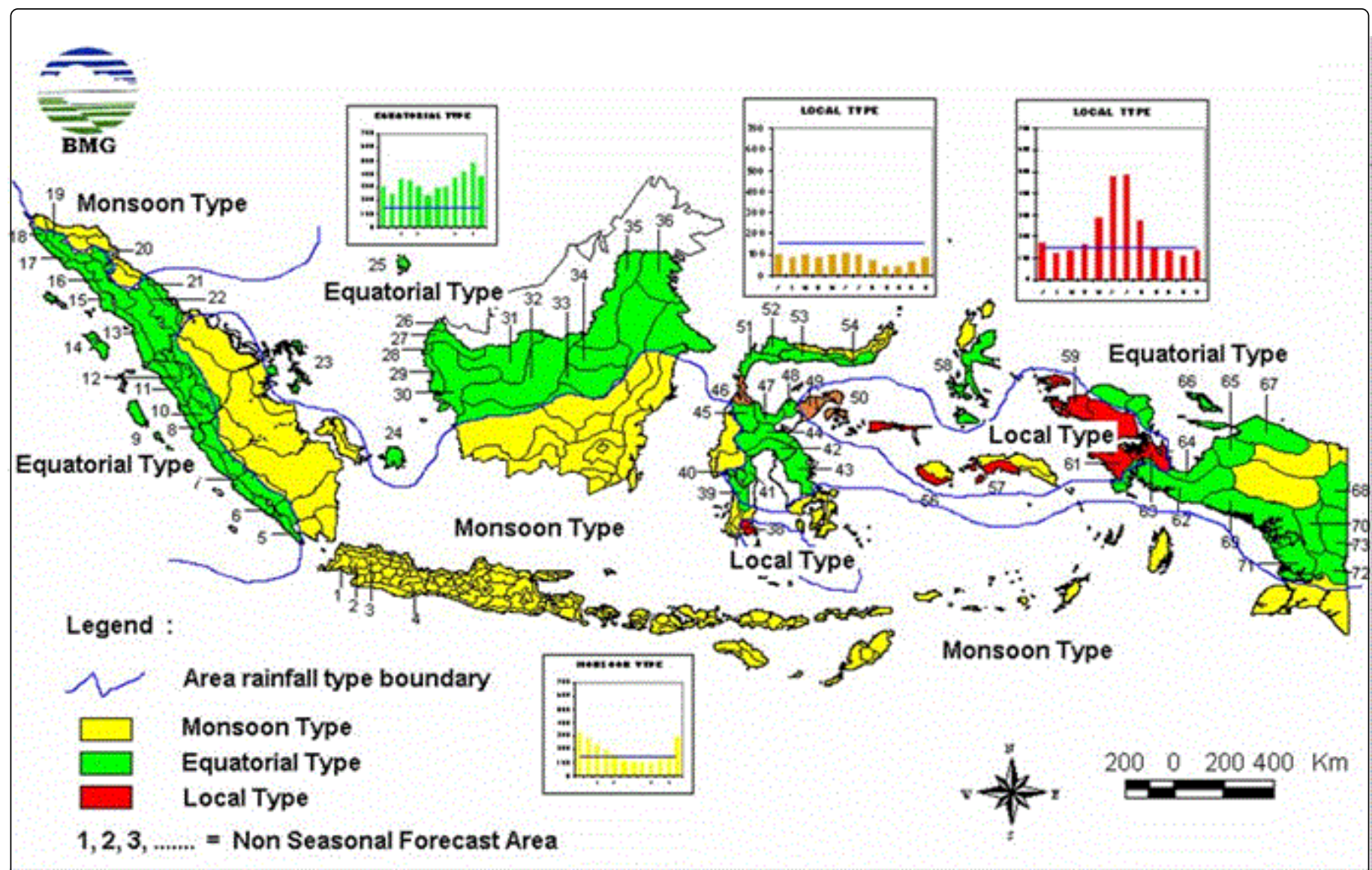

Figure 4: Rainfall Type over Indonesia to be analyzed for solar power energy (BMG).

\section{Summary}

The global mapping of the solar energy power may present that most of the area with sun shining every time of the year to have solar energy to be utilized for the electricity especially over the oceans (Pacific-, Atlantic- and Indian Oceans) and over the deserts of the continents (Africa with Sahara desert, Asia with Gobi and Arab deserts and Australia especially the desert in the interior Australia Continent). Areas of Indonesia maritime continent region are closed with Australian Continent are the appropriate area for solar energy power.

The exploration data toward establishing the solar thermal power plant, the proper area has very good and excellent places for solar thermal power plant expanding toward America continent both northern and southern parts. Indonesia maritime continents categorizes as good area with annual average solar irradiance between 1000-1600 KW Hour/meter Square.

The theoretical developing study will focus on the area of cloudiness with studying rainfall type over maritime continent, the good area to be exploited the solar energy power for solar thermal power plant is the area having less of number rainfall over monsoonal and local type such as most of islands of Java (especially middle and eastern), Bali, Lombok up to Timor, some area of central and north Celebes, most of Moluccas islands and some area of western of Western Papua. Such that, further study using proper meteorological data to be proposed.

\section{References}

1. Badan Meteorologi dan Geofisika (1998) Pola Hujan Indonesia

2. International Energy Agency (2011) Solar Energy Perspectives Executive Summary

3. Cédric P (2005) International Energy Agency: The Present and Future use of Solar Thermal Energy. Solar thermal energy pp: 1-8.

4. http://eesc.columbia.edu/courses/ees/climate/lectures/radiation/

5. http://www.keu92.org/uploads/Search\%20engineering/The\%20Use $\% 20$ Of $\% 20 \% 20$ Solar\%20Energy\%20In\%20Electricity\%20Production.pdf

6. http://www.ugm.ac.id/id/news/5549solar.energy.development.is.wide.open

7. Mills DR (2004) Advances in solar thermal electricity Technology. Solar Energy 76: 19-31.

8. EurObserv ER (2005) Solar thermal barometer. Systèmes Solaires 168: 39-56.

9. Beniston M, Douglas G, Adhikary S, Andressen R, Guisan A, et al. (1996) Impacts of climate change on Mountain regions. Sci Tech Anal, pp: 191-213.

10. Iman F, Abou-E N (2015) Demographic, socioeconomic and environmental changes affecting circulation of neglected tropical diseases in Egypt. Asian Pac J Trop Med 8: 881-888.

11. McCaulJr EW, Cohen C (2002) The impact on simulated storm structure and Intensity of variations in the mixed layer and moist layer depths. Mon Wea Rev 130: 1722-1748.

12. Wilcox RR (1998) A note on the Theil-Sen regression estimator when the regressor is random and the error term is heteroscedastic. Biom J 40: 261-268. 